\title{
Anterior and Posterior Approach Results for Treatment of Cervical Myelopathy in the Elderly: A 10-Year Experience in a Mexican Institution
}

\author{
Mauricio Daniel Sánchez-Calderón1, María Elena Córdoba-Mosqueda ${ }^{{ }^{*}}$, \\ José Ramón Aguilar-Calderón', Carlos René Domínguez-Herz², Diego Ochoa-Cacique1, \\ Daniel Alejandro Vega-Moreno', Victor Andrés Reyes-Rodriguez ${ }^{3}$, Ulises García-González, \\ Abraham Ibarra-de la Torre ${ }^{1}$, Rodrigo Efraín Hernández-Reséndiz ${ }^{4}$
}

${ }^{1}$ Department of Neurosurgery, Hospital Central Sur de Alta Especialidad de Alta Especialidad de PEMEX, Periferico sur 4091, Fuentes del Pedregal, Tlalpan, México City, México

${ }^{2}$ Department of Neurosurgery, Hospital Regional de Alta Especialidad “Centenario de la Revolución Mexicana” ISSSTE

Cuernavaca, Palo Escrito, Emiliano Zapata

${ }^{3}$ Department of Neurosurgery, Hospital Central Norte PEMEX, Mexico City, México

${ }^{4}$ Department of Neurosurgery, Hospital Ángeles Clínica Londres, Mexico City, Mexico

Email: md.sanchez.neurocirugia@gmail.com, ^dramaelenacmosqueda@gmail.com, jcalderon02@yahoo.com, saludneurologica@hotmail.com,diego2doc@gmail.com,d2206_@hotmail.com,neurovican@hotmail.com, ulises.med@gmail.com, abraham_ibarra2017@outlook.com,drrodrigoehr@gmail.com

How to cite this paper: Sánchez-Calderón, M.D., Córdoba-Mosqueda, M.E., AguilarCalderón, J.R., Domínguez-Herz, C.R., OchoaCacique, D., Vega-Moreno, D.A., ReyesRodriguez, V.A., García-González, U., Ibarrade la Torre, A. and Hernández-Reséndiz, R.E. (2021) Paper Title. Open Journal of Orthopedics, 11, 207-219.

https://doi.org/10.4236/ojo.2021.117020

Received: June 18, 2021

Accepted: July 20, 2021

Published: July 23, 2021

\section{Copyright $\odot 2021$ by author(s) and} Scientific Research Publishing Inc. This work is licensed under the Creative Commons Attribution International License (CC BY 4.0).

http://creativecommons.org/licenses/by/4.0/ (c) (i) Open Access

\begin{abstract}
Introduction: Degeneration of the cervical spine (CDSD) prevalence is nearly $90 \%$ by the 7 th decade. This is the first research that compares the outcomes between the Anterior Approach (AA) and Posterior Approach (PA) to cervical myelopathy $(\mathrm{CM})$ in the elderly. Materials and Methods: A retrospective observational study of electronic health records at the Hospital Central Sur de Alta Especialidad (HCSAE), PEMEX from January 2010 to May 2020 with patients older than 60 years submitted to cervical surgery. For the analysis we elaborated two groups according to the surgical approach: AA vs PA; we analyzed the trans-operative behavior, the immediate outcome, and after 3 months, 6 months, and 1 year. Results: As a total of 145 patients, the prevalence of CM in elderly was the $63.8 \%$ with a median age of $69(64-75)$ years. We found statistical differences in strength outcome only in the $\mathrm{P} 3 \mathrm{~m}(\mathrm{p}=$ 0.011 ), for sensitivity we found major prevalence of affection in the PA group. We didn't report a significant difference in the Neck Disability Index (NDI) at all measures, but the PA presented a major incapacity. The Nurick scale results were significant in all stages $(\mathrm{p}<0.05)$; and presented improvement compared with presurgical period $(\mathrm{p}<0.001)$. Discussion: Patients show sig-
\end{abstract}


nificant improvements in outcome measures with either anterior or posterior surgery. Both approaches are highly efficacious in preventing neurologic deterioration and in most cases improve neurological function with appropriate postoperative management like rehabilitation, pain management, and psychological support. Conclusion: The patients submitted to surgical medullary decompression presented a favorable outcome despite the age and the higher prevalence of comorbidities; whereby we favor the surgical treatment in all patients in a case-to-case selection to generate a positive impact on functional outcomes.

\section{Keywords}

Cervical Spine, Surgical Approach, Elderly, Cervical Myelopathy, Cervical Degenerative Spine Disease

\section{Introduction}

Degeneration of the cervical spine is part of the natural process of aging, with $30 \%$ of the population showing degeneration in the 4 th decade and $90 \%$ by the 7 th decade. The most common cause of spinal cord dysfunction in the elderly population is cervical myelopathy $(\mathrm{CM})$, surgery is the primary treatment reporting excellent outcomes in the general population, but there are scarce publications to review the outcomes in the Mexican and Latin-American elderly population [1] [2].

In 1972, Nurick described a six-grade system based on the "difficulty in walking" and postulated that the established disability in CM occurs early in the disease and barely progresses [3].

The optimal management strategy for CM secondary to a cervical degenerative spine disease (CDSD) remains controversial because of the natural history of the disease and the degree of neurological progression [4].

Elderly patients with CM often present with a multilevel disease, the literature considers the treatment with laminoplasty rather than anterior fusion in case of failure of the conservative therapy [5]. This is the first research that describes and compares the outcomes between the Anterior Approach (AA) and Posterior Approach (PA) to treat CM in the elderly in the Mexican population [6].

\section{Surgical Approaches}

\section{- Anterior Approach (Figure 1)}

AA is the most anatomical technique with minimal collateral soft tissue damage, the indications are clear in spinal pathology between $\mathrm{C} 3$ and $\mathrm{T} 1$ with the affection in the anterior components of the spine (disk herniation, vertebral osteophytes).

The technique requires a supine position with a slight hyperextension of the head and exposition of the cervical region. The incision is paramedian and can 
be transverse, oblique, or longitudinal; followed by dissection of subcutaneous tissue and cervical fascia to expose the vertebral bodies. If it is necessary, the surgeon can realize the discectomy and medullary decompression [7].

- Posterior Approach (Figure 2)

This technique is for multisegmental (2 or more) spine levels with degenerative changes and ossification of the posterior longitudinal ligament (OPLL).

The surgical position of the patient is prone, using a Mayfield head clamp or a horseshoe headrest and a slight flex of the cervical spine. This procedure requires a midline incision, dissection, and a detachment of the muscles from the respective spinous process, taking care of lateral dissection because of the trajectory of the vertebral artery.

Posterior to the exposure of vertebral laminae, the following step is to dissect the interlaminar ligament and the laminoplasty or laminectomy to decompress the cervical canal.

The contraindications for this approach are in cases of instability and with diseases of the anterior structures [7].

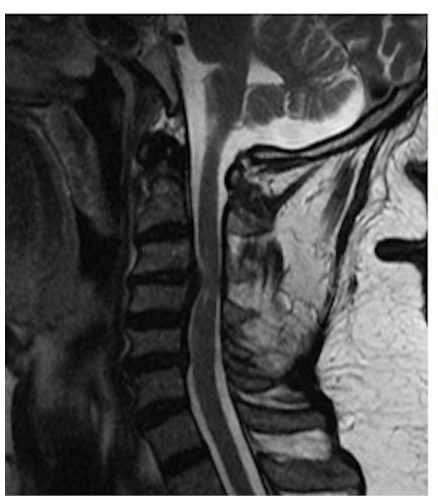

(a)

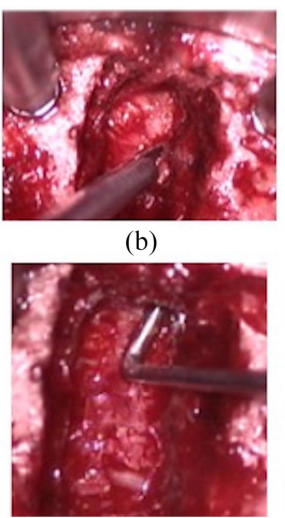

(c)

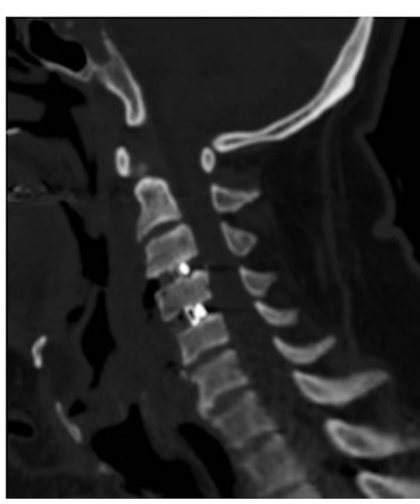

(d)

Figure 1. A 67-year-old man with a history of hypoesthesia of both arms and severe cervicalgia; (a) sagittal T2 Magnetic Resonance Image (MRI) with cervical canal stenosis at $\mathrm{C} 3 \mathrm{C} 4$ with medullary compression; (b, c) trans-operative pictures of $\mathrm{C} 3 \mathrm{C} 4$ after discectomy and adequate decompression; (d) postoperative Computed Tomography (CT) scan with evidence of prosthesis position and adequate spinal canal caliber.

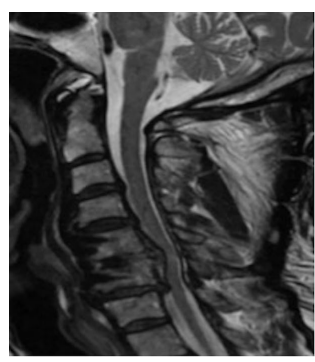

(a)

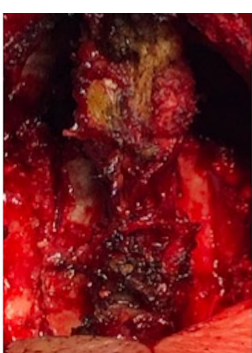

(b)

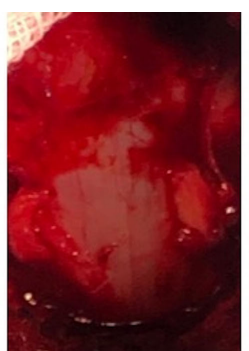

(c)

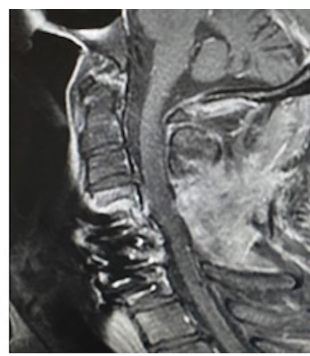

(d)

Figure 2. A 60-year-old man with walking instability, cervicalgia, and previous anterior arthrodesis; showing in sagittal T2 MRI (a) spinal canal stenosis; (b, c) trans-operative images of laminae and dura-mater after decompression; (d) postoperative sagittal MRI showing posterior decompression of spinal canal. 


\section{Materials and Methods}

A retrospective search of electronic health records at the Hospital Central Sur de Alta Especialidad, PEMEX (HCSAE), from January 2010 to May 2020. We selected the cases using the code M500-Myelopathy secondary to the degenerative process of an intervertebral disk from the International Classification of Diseases (ICD-10). For this study, the inclusion criteria were:

- Subjects older than 60 years.

- Myelopathy secondary to degenerative disease.

- Follow-up at 1 year.

- Subjects submitted to surgical treatment previously accepted consents.

We excluded patients with myelopathy secondary to different etiology than degenerative, for example traumatic, infectious, tumors, etc. Also, we removed patients with an incomplete follow-up at 1 year, and those who followed conservative management.

\section{Statistical Analysis}

Demographic data were reported as median, range, frequency, and prevalence. We elaborated 2 groups according to the surgical approach: AA vs PA; and analyzed the trans-operative behavior, the immediate outcome, and after 3 months (P3m), 6 months (P6m), and 1 year (P1y) with the following variables:

- Complications: Defined as all the trans-operative and postoperative undesirable events that impact directly in patient evolution and they could be classified by type: neurological (CSF fistulae, laryngeal nerve lesion, nerve roots lesion), systemic (infection, esophageal lesion, hypertension, arrhythmias), related to anesthesia (delirium).

- Neck Disability Index (NDI)-The NDI is an international classification for disability related to CM. This scale has 10 items, seven related to activities of daily living, two related to pain, and one item related to concentration. Each item is scored from 0 to 5 and the total is expressed as a percentage. Higher scores correspond to greater disability [8].

- Nurick Scale: Table 1 describes the clinical criteria of the Nurick scale. This scale grades myelopathy and patients' performance. For the analysis, we dichotomized the results in $<3$ or $\geq 3$ according to the severity of myelopathy [3].

- Sensitivity: The term "affected" refers to symptoms during the evolution and follow-up in the patients, characterized by dysesthesia, hypoesthesia, altered proprioception, agraphaesthesia, and absence of two-point discrimination.

- Strength: The International scale of Daniels (see Table 1) describes the grade of affection at muscular strength. For this study, we took dichotomized the results as severe results $<3$ and mild $\geq 3$ [7].

For the analysis between groups, we performed a Mann-Whitney $U$ test for quantitative variables, and a chi-square test for categorical. The analysis of the results in each approach was realized with Friedman Test for quantitative parameters and Cochran's test for categorical values. 
Table 1. Nurick and Daniel's scales.

\begin{tabular}{|c|c|}
\hline \multicolumn{2}{|r|}{ Nurick Scale } \\
\hline Grade & Characteristics \\
\hline 0 & Signs or symptoms of root involvement but without evidence of spinal cord disease \\
\hline 1 & Signs of spinal cord disease but no difficulty in walking \\
\hline 2 & Slight difficulty in walking which does not prevent full-time employment \\
\hline 3 & $\begin{array}{l}\text { Difficulty in walking which prevents full-time employment or the ability to do all } \\
\text { housework, but which is not so severe as to require someone else's help to walk }\end{array}$ \\
\hline 4 & Able to walk only with someone else's help or with the aid of a frame \\
\hline 5 & Chair bound or bedridden \\
\hline \multicolumn{2}{|r|}{ Daniel's Scale } \\
\hline Grade & Definition \\
\hline 0 & Absence of muscular contraction \\
\hline 1 & Visible or palpable muscular contraction without any movement. \\
\hline 2 & Movement of the extremity without defeating gravity \\
\hline 3 & Movement against gravity \\
\hline 4 & Movement against gravity and resistance diminished strength \\
\hline 5 & Normal strength \\
\hline
\end{tabular}

Calculations were conducted using IBM SPSS 27.0 statistical analysis software, with the significance threshold set at $\mathrm{P}<0.05$.

The study design conformed to the Declaration of Helsinki and local regulations; patients signed their informed consent for admission and surgery and for reporting their results and data.

\section{Results}

We found 145 patients with the inclusion criteria, representing a prevalence of $63.8 \%$ of the cases with cervical myelopathy in the HCSAE. Table 2 presents the demographic and general characteristics of our sample. The age of presentation was $69(64-75)$ years, and masculine was the most prevalent gender.

Laterality of the symptoms with more prevalence was bilateral, presented in $60.7 \%$ of our sample. The median number of affected levels was $2(1-3)$, being C5C6 the most prevalent (40\%) followed by C4C5 (36.8\%) and C3C4 (21.6\%).

For the first treatment, $92.4 \%$ of the patients started with conservative treatment like physical therapy and non-steroid anti-inflammatory drugs (NSAIDs) without a significant remission of symptoms; becoming candidates for surgical management.

The comorbidities with major frequency were systemic blood hypertension (51\%), Diabetes mellitus type 2 (29\%) and urologic diseases (10.3\%). Other comorbidities (psychiatric diseases, cardiopathies, nephropathies, neuropathies, cancer, rheumatoid arthritis, osteoporosis, hematologic disorders, and gastropathy) presented a prevalence of less than $5 \%$ per each one. 
Table 2. Demographic characteristics $(n=145)$.

n (\%)

\begin{tabular}{|c|c|}
\hline Gender & \\
\hline Feminine & $56(38.6)$ \\
\hline Masculine & $89(61.4)$ \\
\hline \multicolumn{2}{|l|}{ Laterality } \\
\hline Left & $31(21.4)$ \\
\hline Right & $26(17.9)$ \\
\hline Bilateral & $88(60.7)$ \\
\hline \multicolumn{2}{|l|}{ Levels } \\
\hline$C 2 C 3$ & $1(0.7)$ \\
\hline C3C4 & $55(37.9)$ \\
\hline$C 4 C 5$ & $88(60.7)$ \\
\hline C5C6 & $98(67.6)$ \\
\hline C6C7 & $43(29.7)$ \\
\hline$C 7 T 1$ & $3(2.1)$ \\
\hline \multicolumn{2}{|l|}{ Initial Treatment } \\
\hline Conservative & $134(92.4)$ \\
\hline Surgical & $11(7.6)$ \\
\hline \multicolumn{2}{|l|}{ Comorbidities } \\
\hline Systemic Blood Hypertension & $74(51.0)$ \\
\hline Diabetes Mellitus type 2 & $42(29.0)$ \\
\hline Urologic & $15(10.3)$ \\
\hline Others & $41(28.3)$ \\
\hline
\end{tabular}

\subsection{Characteristics of the Groups and Perioperative Results} (Table 3)

The median age of presentation was significantly older in the PA group $(\mathrm{U}=$ 1697.00, $\mathrm{p}=0.008)$ with $71(67-77.5)$ years. Masculine was the most prevalent gender in both approaches. However, we found a statistical difference between groups $\left(\mathrm{x}^{2}(1)=7.533, \mathrm{p}=0.006\right)$. The median time of the symptoms did not present a significant difference between groups $(U=2275.00, p=0.823)$, neither the number of affected levels $(\mathrm{U}=2286.00, \mathrm{p}=0.847)$.

We reported a surgical time of $210(156-240)$ minutes for AA and 150 (120 180) minutes for PA where we appreciated a notable difference $(\mathrm{U}=1275.50, \mathrm{p}$ $=0.001)$ between them. Surgical bleeding $(\mathrm{U}=2027.00, \mathrm{p}=0.203)$ and the median length of hospitalization $(U=2129.500, p=0.455)$ did not present a significant difference between both groups.

Twenty-two patients presented complications, being more prevalent in AA, without a statistical difference against PA $\left(\mathrm{x}^{2}(1)=1.261, \mathrm{p}=0.261\right)$. In Figure 3, we present the different frequencies of the complications, those related to the anesthesia management and the CSF leak prevailed in AA, and in PA the Delirium. 


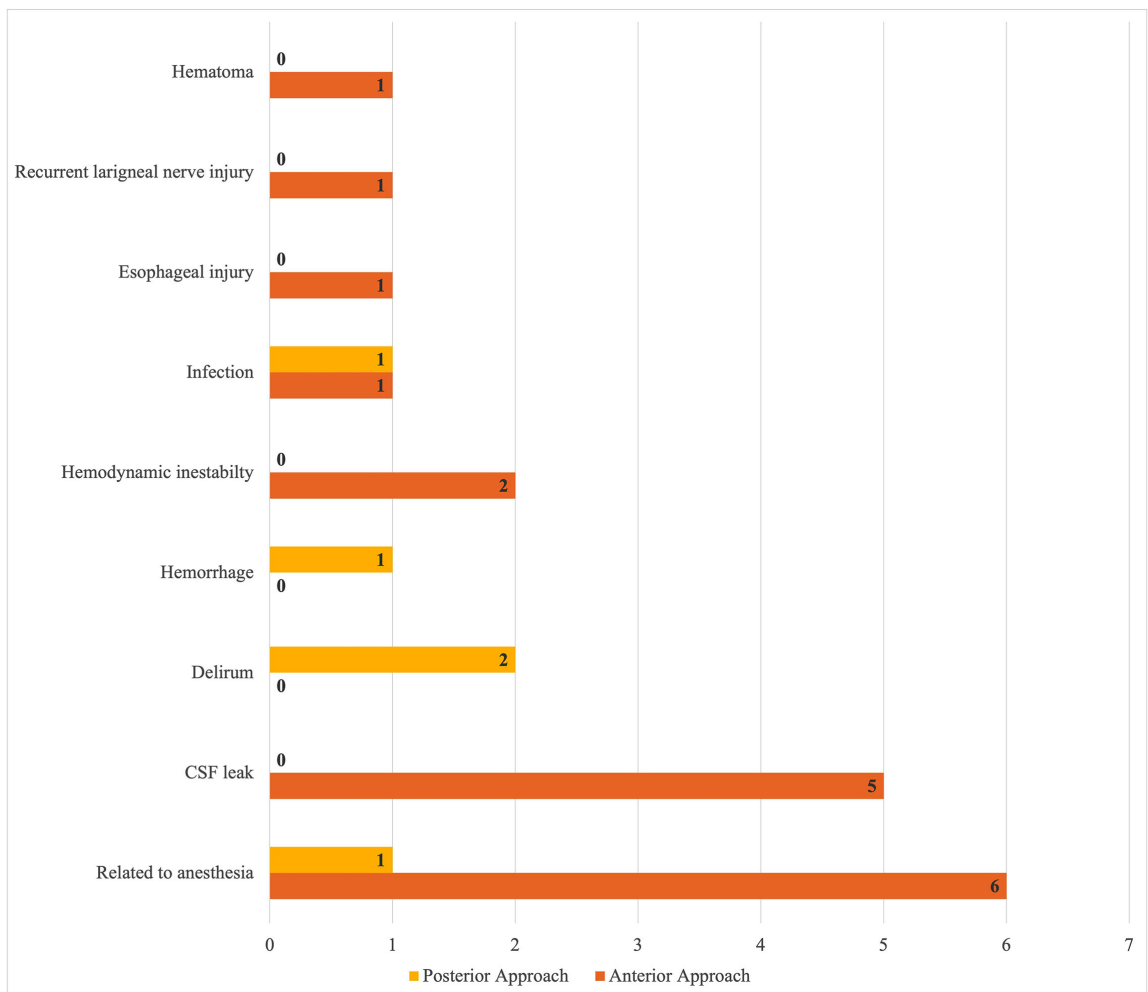

Figure 3. Surgical complications.

Table 3. General and Surgical variables of Anterior and Posterior groups ( $\mathrm{n}=145)$.

\begin{tabular}{cccc}
\hline & $\begin{array}{c}\text { Anterior Approach } \\
(\mathbf{n}=\mathbf{9 7})\end{array}$ & $\begin{array}{c}\text { Posterior Approach } \\
(\mathbf{n}=\mathbf{4 8})\end{array}$ & $\mathbf{p}$ \\
\hline Age & $69(63-673.5)$ years & $71(67-77.5)$ years & $0.008^{*}$ \\
\hline Gender & & & $0.018^{*}$ \\
\hline Feminine & $44(45.4 \%)$ & $12(25 \%)$ & \\
Masculine & $53(59.6 \%)$ & $36(75 \%)$ & 0.823 \\
\hline Evolution time & $5(3-16)$ years & $5(2-17)$ years & 0.847 \\
\hline Number of levels & $2(2-2)$ & $2(2-3)$ & \\
\hline Surgical Variables & & & $0.001^{*}$ \\
\hline Surgical time & $210(156-240)$ min & $150(120-180)$ min & 0.203 \\
Bleeding & $150(90-250) c c$ & $200(100-300) \mathrm{cc}$ & 0.455 \\
\hline Days of hospitalization & $6(4-11)$ days & $5(4-10)$ days & 0.261 \\
\hline Complications & $17(17.5 \%)$ & $5(10.4 \%)$ &
\end{tabular}

*Statistical significative.

\subsection{Outcome Results (Table 4)}

In the variable of strength, we found a significant difference between the approaches in the presurgical period $\left(\mathrm{x}^{2}(1)=9.003, \mathrm{p}=0.003\right)$ and at $\mathrm{P} 3 \mathrm{~m}\left(\mathrm{x}^{2}(1)=\right.$ 6.501, $\mathrm{p}=0.011)$. IP $\left(\mathrm{x}^{2}(1)=3.682, \mathrm{p}=0.055\right), \mathrm{P} 6 \mathrm{~m}\left(\mathrm{x}^{2}(1)=0.096, \mathrm{p}=0.757\right)$ and P1y $\left(\mathrm{x}^{2}(1)=9.758, \mathrm{p}=0.384\right)$ did not show a statistical difference. Both groups presented a statistical improvement in strength $\left(A A: x^{2}(4)=51.203, p<\right.$ 
0.001; PA: $\left.\mathrm{x}^{2}(4)=4.926, \mathrm{p} \leq 0.001\right)$ and no clinical deterioration compared with the presurgical stage.

In both approaches, the patients showed a significant sensitivity improvement compared with the presurgical state $\left(\mathrm{AA}: \mathrm{x}^{2}(4)=91.051, \mathrm{p}<0.001\right.$; PA: $\mathrm{x}^{2}(4)=$ $15.094, \mathrm{p}=0.005)$, however; we found differences in measures at $\mathrm{P} 3 \mathrm{~m}\left(\mathrm{x}^{2}(1)=\right.$ $6.638, \mathrm{p}=0.010), \mathrm{P} 6 \mathrm{~m}\left(\mathrm{x}^{2}(1)=13.658, \mathrm{p}=0.001\right)$, and P1y $\left(\mathrm{x}^{2}(1)=11.065, \mathrm{p}=\right.$ $0.001)$, with a major prevalence of the affection in the PA group.

The difference in the median percentage index of NDI between groups was not significant (Presurgical: $U=2040.00, p=0.225$; IP: $U=2287.50, p=0.923$; P3m: $U=2121.00, p=0.422 ; \mathrm{P} 6 \mathrm{~m}: \mathrm{U}=2262.00, \mathrm{p}=0.765 ; \mathrm{P} 1 \mathrm{y}: \mathrm{U}=2153.5, \mathrm{p}=$ $0.394)$ presenting a major incapacity in the PA group.

Table 4. Presurgical and Follow-up results.

\begin{tabular}{|c|c|c|c|}
\hline & $\begin{array}{l}\text { Anterior Approach } \\
\qquad(\mathrm{n}=97)\end{array}$ & $\begin{array}{l}\text { Posterior Approach } \\
\qquad(\mathrm{n}=48)\end{array}$ & $\mathrm{p}$ \\
\hline Strength $(<3)$ & n (\%) & n (\%) & \\
\hline Presurgical & $21(21.6)$ & $22(45.8)$ & $0.003^{*}$ \\
\hline Immediate postsurgical & $5(5.2)$ & $7(14.6)$ & 0.055 \\
\hline Postsurgical3 months & $3(3.2)$ & $7(14.6)$ & $0.011^{*}$ \\
\hline Postsurgical6 months & $3(3.2)$ & $2(4.3)$ & 0.757 \\
\hline Postsurgical 1 year & $3(3.2)$ & $3(6.3)$ & 0.384 \\
\hline $\mathrm{p}$ & $<0.001^{\star}$ & $<0.001^{\star}$ & \\
\hline Sensitivity (affected) & n (\%) & n (\%) & \\
\hline Presurgical & $66(68)$ & $37(77.1)$ & 0.259 \\
\hline Immediate postsurgical & $53(54.6)$ & $32(66.7)$ & 0.166 \\
\hline Postsurgical3 months & $31(32)$ & $26(54.2)$ & $0.010^{*}$ \\
\hline Postsurgical 6 months & $26(26.8)$ & $28(58.3)$ & $0.001^{\star}$ \\
\hline Postsurgical 1 year & $22(22.7)$ & $24(50)$ & $0.001^{\star}$ \\
\hline $\mathrm{p}$ & $<0.001^{\star}$ & $0.005^{\star}$ & \\
\hline $\mathrm{NDI}+$ & Index (range) \% & Index (range) \% & \\
\hline Presurgical & $30(10-48)$ & $24(2.5-45)$ & 0.225 \\
\hline Immediate postsurgical & $12(0-30)$ & $12.5(0-40)$ & 0.923 \\
\hline Postsurgical3 months & $5(0-11)$ & $7.5(0-24.5)$ & 0.422 \\
\hline Postsurgical 6 months & $2(0-10)$ & $0(0-15)$ & 0.765 \\
\hline Postsurgical 1 year & $0(0-5)$ & $0(0-10)$ & 0.394 \\
\hline $\mathrm{p}$ & $<0.001^{\star}$ & $<0.001^{\star}$ & \\
\hline Nurick $(\geqq 3)$ & n (\%) & n (\%) & \\
\hline Presurgical & $26(26.8)$ & $24(50)$ & $0.006^{*}$ \\
\hline Immediate postsurgical & $27(27.8)$ & $25(52.1)$ & $0.004^{*}$ \\
\hline Postsurgical3 months & $27(27.8)$ & $25(52.1)$ & $0.004^{\star}$ \\
\hline Postsurgical 6 months & $18(18.6)$ & $17(35.4)$ & $0.026^{*}$ \\
\hline Postsurgical 1 year & $12(12.4)$ & $16(33.3)$ & $0.003^{*}$ \\
\hline $\mathrm{p}$ & $<0.001^{\star}$ & $<0.001^{*}$ & \\
\hline
\end{tabular}

${ }^{\star}$ Statistical significative, $\uparrow$ Neck Disability Index. 
There was a significant difference in the NDI results between the presurgical and postsurgical stages in each group (AA: $\mathrm{x}^{2}(4)=246.079, \mathrm{p}<0.001$; PA: $\mathrm{x}^{2}(4)$ $=86.068, \mathrm{p}<0.001)$. Post hoc analysis with Wilcoxon signed-rank tests was conducted with a Bonferroni correction, resulting in a significance level set at $\mathrm{p}$ $<0.010$. We only found no significant differences between the P6m and P1y in the PA $(\mathrm{Z}=-1.472, \mathrm{p}=0.140)$, the rest of the values were statistically different between them.

The Nurick scale results showed a statistical difference during in all the stages (Presurgical: $\mathrm{x}^{2}(1)=7.647, \mathrm{p}=0.006 ; \mathrm{IP}: \mathrm{x}^{2}(1)=8.208, \mathrm{p}=0.004 ; \mathrm{P} 3 \mathrm{~m} \mathrm{x}^{2}(1)=$ 8.208, $\mathrm{p}=0.004$; P6m: $\mathrm{x}^{2}(1)=4.985, \mathrm{p}=0.026$; P1y: $\mathrm{x}^{2}(1)=9.055, \mathrm{p}=0.003$ ). Both groups presented an improvement compared with the presurgical period $\left(\mathrm{x}^{2}(4)=33-091, \mathrm{p}<0.001\right)$.

\section{Discussion}

$\mathrm{CM}$ is one of the most common diseases in the elderly population, including almost $90 \%$ of patients in the seventh decade of life; it is more often in the male population (1.12:1, M:F). The symptoms are sensitive alterations, weakness, urine incontinence, and in the most severe cases, quadriplegia secondary to the stenosis of the spinal canal [9]. Our population has similar demographic aspects to those reported in the current literature.

The pathological changes in the spine during the elderly are a combination of disk herniations that occur because of dysfunction, instability, and spinal stenosis. These changes occur because of the late instability and early stabilization secondary to bony overgrowth, leading to disturbing with more frequency $\mathrm{C} 6 \mathrm{C} 7$ (60\%), followed by C5C6 (40\%) and C4C5 (5\%) [10]. In our series, the most affected levels were $\mathrm{C} 4 \mathrm{C} 5$ and $\mathrm{C} 5 \mathrm{C} 6$; $\mathrm{C} 3 \mathrm{C} 4$ occupied third place, derived from the changes in motion at this level [6].

Conservative treatment includes physical therapies, including intermittent cervical traction, heat therapy, and medications; these therapies may offer symptomatic relief with NSAIDs, steroids, and/or muscle relaxants for neck pain or paresthesias. The recommendation is to start the conservative treatment in patients with mild CDSD [18]. The proportion of patients who converted to surgery after failed nonoperative care ranged from $4 \%$ to $40 \%$ during 3 of 7 years [5].

\subsection{Approach Analysis}

Based on the characteristics of each patient, the choice of the AA is in patients with normal to kyphotic alignment because PA may further cause kyphosis secondary to the destabilization. When an indirect decompression is warranted, the PA can be used. This approach is for patients with neutral or lordotic cervical spine alignment and is quite helpful in patients with multilevel compression and congenital stenosis, usually involving C3-C7. Posterior decompression provides the spinal cord with more space, moving away from the disk/bony ridges that are 
compressing anteriorly [11] [12] [13].

In our study, we performed the AA for younger patients than the PA group. The international literature encourages the anterior techniques to treat younger patients and with less severe impairment and more focal cervical pathology, as we reported [14].

The results in the perioperative variables that we describe showed similar results to those in the international literature. Blood loss is higher in the PA because of a bigger muscle dissection. The literature reports a stronger association between the PA and the necessity of blood transfusion (1.38\% AP, 7.20\% PA) [14] [15].

Surgical time presents differences between the approaches. During the dissection, the AA demands more time for the vital structures that surrounded the incision, like the trachea, esophagus, carotid artery, jugular vein, and recurrent laryngeal nerve; in PA, the dissection involves only muscles and fascia minimizing the surgical time [9] [14].

Various studies have shown variations in outcomes after cervical spine surgery secondary to the patient's characteristics and surgical factors. Older patients were at greater risk of encountering several complications, and gender was a common risk factor depending on the complication.

Nationwide Inpatient Sample showed that older patients had a higher risk of complications, such as cardiac and respiratory complications. This study identified common non-infection complications and corresponding risk factors after selected cervical spine surgery. The cause of these complications is unclear. They may be related to anesthesia or opioid use, particularly since almost all patients undergoing common orthopedic and soft tissue surgical procedures had been previously found to receive opioids [16]. Despite the higher prevalence of comorbidities in the Mexican population, the frequency of postoperative complications presented in our sample was low, probably associated with perioperative management in our institution [17].

\subsection{Functional Outcomes}

- Strength

The rate of strength recovery in the postsurgical stages in our elderly patients could be secondary to the age-related changes in their spinal cord, including a decrease in $\gamma$-motor neurons, synaptic and dendritic elements, the number of anterior horn cells and number of myelinated fibers in the corticospinal tract and posterior funiculus; may have unassociated comorbidities that may impede their ability to perform the simple tasks, such as locomotor diseases (hip and knee osteoarthritis), sarcopenia, diabetic neuropathy, or urinary incontinence; have reduced physiological reserves and, as a result, are less tolerant to physical assault such as that represented by surgery [18].

- Sensory deficit

Our data reports that the patients with PA decompression remained with 
mild-to-moderate symptoms after 3 months of the surgery compared with AA. PA can produce progressive kyphosis, expansion of the OPLL, and indirect decompression of nerve roots and spinal canal, in the other side; the AA makes a direct decompression and resection of the OPLL with better long-term sensitivity outcomes [19].

- NDI

Patients submitted to cervical surgery presented significant improvement in their NDI index in all time intervals of follow-up, no matter the approach achieving almost the $100 \%$ after 5 years of follow-up [19]. When patients make improvements in pain and disability after spine surgery in the first three months; they are likely to continue to improve and have successful clinical outcomes in one year. Part of the therapy role is to maximize the long-term follow-up with reconditioning functional strength, mobility and postural control of the upper body. In addition, with therapy, patients can learn the most effective nonpharmacological pain management [20].

- Nurick scale

Although both surgical approaches for CM are effective in the elderly, these patients are less effective at translating neurological improvements into functional recovery (18). The differences presented in the measurements at each stage of the evaluation between the AA and PA approaches are because the PA has a major prevalence since the presurgical stage compared with the AA. However, both approaches presented a good recovery after 1 year of follow-up, coinciding with the conclusions of previous reports that both approaches are highly efficacious in preventing neurologic deterioration and in most cases improve neurological function [21].

\section{Conclusions}

International literature recommends realizing AA to treat multilevel $\mathrm{CM}$ in the elderly when involved in less than 3 surgical segments. PA may be the elective method for treatment multilevel ( $\geq 3)$ [15].

Adequate surgical decompression is necessary to get a favorable long-term outcome, however, is important to recognize the previous functional limitations related to comorbidities.

Appropriate perioperative management is crucial to get a satisfactory result. The selection of the approach should accord to the surgeon's abilities, the patient's characteristics, and the anesthetic support. The postsurgical management should include excellent rehabilitation, pain management, and psychological support.

Unlike the international literature reports predictors like comorbidities, age, duration, and severity of symptoms; we could determine that in this series all the patients submitted to surgical medullary decompression presented a favorable outcome despite the age and the higher prevalence of comorbidities in the Mexican population; whereby we favor the surgical treatment in all patients in a case-to-case selection to generate a positive impact on functional outcomes. 


\section{Limitations}

The major limitation of this study is that the analysis was carried out retrospectively, limiting the selection of the approach to criteria and treatment of different surgeons. With this article, we want to encourage the scientific community to carry out future projects, eliminating these limitations.

\section{Conflicts of Interest}

The authors declare no conflicts of interest regarding the publication of this paper.

\section{References}

[1] De la Garza-Ramos, R., Ramhmdani, S., Kosztowski, T., Xu, R., Yassari, R., Witham, T.F., et al. (2017) Prognostic Value of Preoperative Nurick Grade and Time with Symptoms in Patients with Cervical Myelopathy and Gait Impairment. World Neurosurgery, 105, 314-320. https://doi.org/10.1016/j.wneu.2017.05.166

[2] Madhavan, K., Chieng, L.O., Foong, H. and Wang, M.Y. (2016) Surgical Outcomes of Elderly Patients with Cervical Spondylotic Myelopathy: A Meta-Analysis of Studies Reporting on 2868 Patients. Neurosurg Focus, 40, Article No. E13. https://doi.org/10.3171/2016.3.FOCUS1657

[3] Lasanianos, N.G., Triantafyllopoulos, G.K. and Pneumaticos, S.G. (2015) Myelopathy: Nurick Grading System. In: Lasanianos, N.G., Kanakaris, N.K., Giannoudis, P.V., Eds., Trauma and Orthopaedic Classifications, Springer, London. https://doi.org/10.1007/978-1-4471-6572-9_57 http://link.springer.com/10.1007/978-1-4471-6572-9_57

[4] Fehlings, M.G., Ibrahim, A., Tetreault, L., Albanese, V., Alvarado, M., Arnold, P., et al. (2015) A Global Perspective on the Outcomes of Surgical Decompression in Patients With Cervical Spondylotic Myelopathy: Results from the Prospective Multicenter AOSpine International Study on 479 Patients. Spine, 40, 1322-1328. https://doi.org/10.1097/BRS.0000000000000988

[5] Hida, K., Yano, S., Koyanagi, I., Akino, M., Seki, T. and Iwasaki, Y. (2008) Surgical Treatment of Cervical Spondylosis in the Elderly: Surgical Outcomes, Risk Factors, and Complications. Neurologia Medico-Chirurgica, 48, 377-382.

https://doi.org/10.2176/nmc.48.377

[6] Armenta, A.G.P., Martínez, E.E., Gonzalez, R.T., Garfias, A.R., Prado, M.G.S., Armenta, A.G.P., et al. (2018) Epidemiological Panorama of Orthopedic Spine Pathology in Mexico. Coluna/ Columna, 17, 120-123. https://doi.org/10.1590/s1808-185120181702189430

[7] Spinal Disorders (2008) Fundamentals of Diagnosis and Treatment. Springer, Berlin Heidelberg. https://www.springer.com/gp/book/9783540405115

[8] Antoniuk, S.A. (2013) Debilidad Muscular Aguda: Diagnósticos Diferenciales. Revista de Neurología, 57, 149-154. https://doi.org/10.33588/rn.57S01.2013252

[9] Holmes, A., Wang, C., Han, Z.H. and Dang, G.T. (1994) The Range and Nature of Flexion-Extension Motion in the Cervical Spine. Spine, 19, 2505-2510. https://doi.org/10.1097/00007632-199411001-00003

[10] Fakhoury, J. and Dowling, T.J. (2020) Cervical Degenerative Disc Disease. StatPearls Publishing, Treasure Island, FL. https://www.ncbi.nlm.nih.gov/books/NBK560772/ 
[11] Matsumoto, M., Chiba, K., Ishikawa, M., Maruiwa, H., Fujimura, Y. and Toyama, Y. (2001) Relationships Between Outcomes of Conservative Treatment and Magnetic Resonance Imaging Findings in Patients With Mild Cervical Myelopathy Caused by Soft Disc Herniations. Spine, 26, 1592-1598. https://doi.org/10.1097/00007632-200107150-00021

[12] Holly, L.T., Moftakhar, P., Khoo, L.T., Shamie, A.N. and Wang, J.C. (2008) Surgical Outcomes of Elderly Patients with Cervical Spondylotic Myelopathy. Surgical Neurology, 69, 233-240. https://doi.org/10.1016/j.surneu.2007.09.036

[13] Shin, J.H., Steinmetz, M.P., Benzel, E.C. and Krishnaney, A.A. (2011) Dorsal Versus Ventral Surgery for Cervical Ossification of the Posterior Longitudinal Ligament: Considerations for Approach Selection and Review of Surgical Outcomes. Neurosurg Focus, 30, Article No. E8. https://doi.org/10.3171/2010.12.FOCUS10270

[14] Harel, R., Stylianou, P. and Knoller, N. (2016) Cervical Spine Surgery: ApproachRelated Complications. World Neurosurgery, 94, 1-5.

https://doi.org/10.1016/j.wneu.2016.06.099

[15] Fehlings, M.G., Tetreault, L.A., Kurpad, S., Brodke, D.S., Wilson, J.R., Smith, J.S., et al. (2017) Change in Functional Impairment, Disability, and Quality of Life Following Operative Treatment for Degenerative Cervical Myelopathy: A Systematic Review and Meta-Analysis. Global Spine Journal, 7, 53S-69S.

https://doi.org/10.1177/2192568217710137

[16] Radcliff, K., Ong, K.L., Lovald, S., Lau, E. and Kurd, M. (2017) Cervical Spine Surgery Complications and Risks in the Elderly. Spine, 42, E347-E254. https://doi.org/10.1097/BRS.0000000000001799

[17] Ghogawala, Z., Martin, B., Benzel, E.C., Dziura, J., Magge, S.N., Abbed, K.M. and Heary, R.F. (2011) Comparative Effectiveness of Ventral vs Dorsal Surgery for Cervical Spondylotic Myelopathy. Neurosurgery, 68, 622-631. https://doi.org/10.1227/NEU.0b013e31820777cf

[18] Nakashima, H., Tetreault, L.A., Nagoshi, N., et al. (2016) Does Age Affect Surgical Outcomes in Patients with Degenerative Cervical Myelopathy? Results from the Prospective Multicenter AOSpine International study on 479 patients. Journal of Neurology, Neurosurgery \& Psychiatry, 87, 734-740. https://doi.org/10.1136/jnnp-2015-311074

[19] Bhatia, N.N. (2009) Long-Term Outcomes and Complications Following Anterior and Posterior Cervical Spine Surgery. Seminars in Spine Surgery, 21, 177-184. https://doi.org/10.1053/j.semss.2009.05.005

[20] McFarland, C., Wang-Price, S., Gordon, C.R., Danielson, G.O., Crutchfield, J.S., Medley, A. and Roddey, T. (2020) A Comparison of Clinical Outcomes between Early Cervical Spine Stabilizer Training and Usual Care in Individuals following Anterior Cervical Discectomy and Fusion. Rehabilitation Research and Practice, 2020, Article ID: 5946152. https://doi.org/10.1155/2020/5946152

[21] Cleland, J.A., Fritz, J.M., Whitman, J.M. and Palmer, J.A. (2006) The Reliability and Construct Validity of the Neck Disability Index and Patient Specific Functional Scale in Patients with Cervical Radiculopathy. Spine, 31, 598-602. https://doi.org/10.1097/01.brs.0000201241.90914.22 